\title{
HOW GREEN IS MY \\ OCCUPATION \\ CLASSIFICATION?
}

\author{
Andrew Hancock \\ Classification and Standards \\ Statistics New Zealand
}

\begin{abstract}
Economic growth that prevents environmental degradation, biodiversity loss, and reduces climate change is dependent on the identification of new statistical measures, particularly in the way society works. The challenge is to define green jobs and identify green skills and incorporate them into a statistical framework to facilitate integration of economic, social, and environmental components of the labour market. What jobs will stay, what jobs will go and what jobs will emerge? How will the way we work change and can a statistical occupation classification adapt accordingly? The current concept of skill which underpins the Australian and New Zealand Standard Classification of Occupations (ANZSCO) classification may impose a constraint limiting the immediate opportunity for change within the classification structure. However the current ANZSCO classification should be flexible enough to provide an avenue for beginning the process of identifying new occupations in this emerging area of the New Zealand economy. Are green jobs actually new jobs as per existing classification principles or are they just new names for existing jobs? Are there actually new skill requirements that change the way current occupations are described? What are the attributes that need to be measured? This paper seeks to explore the feasibility of defining and classifying green jobs and green skills within the existing ANZSCO framework which may be able to be addressed at the next minor review of the classification.
\end{abstract}

\section{Introduction}

This paper seeks to investigate the feasibility of how a statistical classification, namely the Australian and New Zealand Standard Classification of Occupations (ANZSCO), can address the emerging requirement to measure the growth of green jobs and green skills in the New Zealand labour market. The identification of green jobs or occupations is not an easy process. It is not a case of adding the words 'environmental', 'green', 'sustainability' or 'renewable' to existing titles or tasks contained within job descriptions. The issue is much wider than that. For example, has the New Zealand economy been 'greened' to the extent that new industries, qualifications and occupations are coming into existence, or is the 'greening' of the economy and labour market still in its infancy?

This paper begins by stating the ANZSCO definitions for occupation and job, then discusses some of the international research and will then look at what is meant by the term green jobs and green skills. Options that can be adopted within the existing classification framework will then be discussed.

Opportunity for initial changes to the ANZSCO classification may be able to be addressed at the next minor review in 2013. This will also set the stage for the possibility of making greater conceptual and structural changes when ANZSCO is given its next major review tentatively scheduled for 2017.
The views expressed in this paper on the proposals for ANZSCO are those of the author, and do not necessarily represent those of the Australian Bureau of Statistics or Statistics New Zealand.

\section{Australian and New Zealand Standard Classification of Occupations (ANZSCO)}

The Australian and New Zealand Standard Classification of Occupations (ANZSCO) provides a basis for the standardised collection, analysis, and dissemination of occupation data for Australia and New Zealand. Additionally the common framework provides improved comparability of occupation statistics produced by both countries. The classification framework covers all occupations and jobs in the Australian and New Zealand labour markets undertaken for pay or profit, including jobs occupied by people working for themselves. ANZSCO is the standard occupational framework and so any discussion of how green jobs may be measured in the New Zealand context has to be framed around how ANZSCO is operated.

ANZSCO defines an occupation as "a set of jobs that require the performance of similar or identical sets of tasks. As it is rare for two actual jobs to have identical sets of tasks, in practical terms, an occupation is a set of jobs whose main tasks are characterised by a high degree of similarity". 
ANZSCO defines a job as "a set of tasks designed to be performed by one person for an employer (including selfemployment) in return for payment or profit".

These definitions are then underpinned by the additional criteria of skill level or skill specialisation which are discussed later in this paper. Consequently occupations are defined according to their attributes and then grouped on their similarity into broader categories for statistical and other analysis.

\section{International Research}

New Zealand is not alone in wanting to define and classify green jobs. Significant work has been done by numerous overseas agencies in an attempt to define green jobs, green skills, and describe relevant green economic activities and technologies. Numerous definitions are discussed in the international literature and have been used in differing contexts to reflect the concept of green jobs or green occupations. Many definitions are trying to put a 'green' tinge on economic activities or technologies or on existing tasks within job descriptions without really exploring the concept of 'green' itself.

Some international examples are presented below.

\section{United Nations Environment Programme (UNEP)}

The starting point for identifying a definition for green jobs really begins with the collaborative work of the United Nations Environment Programme (UNEP), International Labour Organisation (ILO), International Organisation of Employers, and the International Trade Union Confederation to produce the 2008 report entitled "Green Jobs: Towards decent work in a sustainable, lowcarbon world." In that report green jobs are defined as "work in agriculture, industry, services, and administration that contributes to preserving or restoring the quality of the environment." This perhaps is a narrow approach but the report goes on to suggest that the notion of green jobs is not absolute and that there are shades of green depending on where and what the jobs apply to.

The key areas of the economy identified in the report for which green jobs might be located include: energy supply, transport, manufacturing, buildings, materials management, retail, agriculture, and forestry. An issue out of this report however which is not clarified is whether all occupations that exist in these economic areas are included or whether it is just low-skilled jobs, professional jobs, or something in-between. The report outlines four key scenarios for the labour market. These are that:

- Additional jobs will be created as new technology and products are developed and introduced;

- Some jobs will be substituted as in shifting from fossil fuel to renewable energy use;

- Jobs will disappear without direct replacement when production processes are discontinued;

- Existing jobs will change and be redefined as skill sets and tasks are greened.
These scenarios are important considerations when determining what occupations to deal with in the ANZSCO classification. In some respects, it is indicating a need to future-proof and ascertain potential areas of development, which is always a conundrum when developing a classification. How far into the future should the classification look to identify future potential jobs that may or may not come into existence or is it actually more practical to include known occupations at the time of developing or reviewing the classification.

The key issue for a statistical organisation in developing a classification such as ANZSCO is having the statistical data to support the process for identifying occupations in decline (and thus removal from ANZSCO) against emerging occupations (and thus addition to ANZSCO). Statistical survey responses do not always equate to job titles or designations used within an industry. Without the correct responses being given, identifying accurate numbers of persons employed in a particular job is not always possible to assist in the classification development.

\section{Connection Research}

The report "Who are the Green Collar Workers? A Definition and Taxonomy" by Ehmcke et al (2009) defined green-collar workers into two categories.

- Managers, professionals and technicians who work in green organisations or who have green skills and responsibilities within other organisations that may not be considered green; and

- $\quad$ Services, clerical, sales and semi-skilled workers who work in a green organisation.” (p19).

This report analysed both the suitability of the Australian and New Zealand Standard Classification of Occupations (ANZSCO) and the Australian and New Zealand Standard Industrial Classification (ANZSIC) as initial frameworks for reporting on green collar workers. The report does stress the need to retain ANZSCO definitions wherever possible in the compilation of the green collar framework it proposes, to enable potential mapping of demographic data (such as Population Census) to the framework. The report noted that identifying green industries, and by inference the ANZSIC classification by itself, was inadequate as a framework. A recommendation was that a matrix of industry by occupation at the one digit level of each classification could help in a conceptual approach.

The framework developed in this report divides some of the ANZSCO Sub-Major Groups into whether they are environmental or sustainable as defined by the authors of the report, rather than using any international definitions of such concepts. This may lead to a narrow approach. In addition the framework is somewhat constrained by the ability to identify an organisation's commitment to the environment ie is it actually green? 
However an issue with this paper is the introduction of the term 'green-collar worker' which may not really be a widely used phrase and which tends to align to the traditional and now somewhat dated blue and white collar taxonomy. The term appears to be used as a synonym for green jobs but needs its own definition, something that is different from that required for a green job. This leads to problems of a different kind. Are we just changing the colour of the collar from blue or white to green because elements of the occupations impact on the quality of the environment or help the planet, or they are environmentally friendly? The approach of grouping occupations within an environmental or sustainable framework may lead the discussion into only covering jobs or occupations that involve the design, manufacture or operation of renewable energy or energy efficiency rather than a wider coverage of green sectors.

\section{United States Bureau of Labor Statistics}

The United States Bureau of Labor Statistics, has in September 2010, published its final definition of 'green jobs'. It defines green jobs as either:

(a) Jobs in businesses that produce goods or provide services that benefit the environment or conserve natural resources;

(b) Jobs in which worker's duties involve making their establishment's production processes more environmentally friendly or use fewer natural resources.

Both definitions are applied to jobs in energy from renewable sources, jobs in energy efficiency, jobs in pollution reduction and removal, recycling and reuse, jobs in natural resources conservation and jobs in environmental compliance, education, and training. These definitions provide a good starting point for addressing the issue within the ANZSCO framework and align very closely with the definition of green jobs used by the New Zealand Career Services rapuara which states: "Green jobs help preserve or improve the state of the natural environment. Jobs may help protect ecosystems, reduce energy consumption, reduce waste and pollution, or inform the public about environmental issues."

In the New Zealand context, the suitability of the definitions would be subject to whether the sectors of energy from renewable sources, energy efficiency, pollution reduction and removal, recycling and reuse, natural resources conservation, and environmental compliance, education, and training are useful. Another issue for the existing ANZSCO is how easy is it to determine which occupations would fall into either definition as the discussion does not address how the environmental aspects are to be measured.

\section{National Center for $O * N E T$ Development}

Another avenue of international research lies with the National Center for Occupational Information Network (O*NET) Development and their report entitled "Greening of the World of Work: Implications for $\mathrm{O}^{*} \mathrm{NET}$, SOC and New and Emerging Occupations (2009)."
In that report green jobs are defined as: "The 'greening' of occupations refers to the extent to which green economy activities and technologies increase the demand for existing occupations, shape the work and worker requirements needed for occupational performance, or generate unique work and worker requirements."

This definition then leads the report to describe three general occupational categories:

- "Green Increased Demand Occupations: The impact of green economy activities and technologies is an increase in the employment demand for an existing occupation;

- Green Enhanced Skills Occupations: The impact of green economy activities and technologies results in a significant change to the work and worker requirement of an existing O*NET-SOC occupation;

- Green New and Emerging Occupations: The impact of green economy activities and technologies is sufficient to create the need for unique work and worker requirements, which results in the generation of a new occupation relative to the O*NET taxonomy."

This categorisation is quite useful in terms of clarifying the scope of the requirements for measuring green jobs in a classifications framework. It also enables occupations currently in ANZSCO to be grouped into a priority schedule for review or assessment, particularly in referencing the first two categories. Obviously the third category would be the highest priority for ANZSCO as this is where the current demand for information really exists.

Out of these general categories, the report identifies twelve green sectors:

\begin{tabular}{|l|l|}
\hline $\begin{array}{l}\text { Renewable Energy } \\
\text { Generation }\end{array}$ & Transportation \\
\hline Energy Efficiency & Green Construction \\
\hline Energy Trading & $\begin{array}{l}\text { Energy and Carbon } \\
\text { Capture }\end{array}$ \\
\hline $\begin{array}{l}\text { Research, Design, and } \\
\text { Consulting }\end{array}$ & Environment Protection \\
\hline Agriculture and Forestry & Manufacturing \\
\hline $\begin{array}{l}\text { Recycling and Waste } \\
\text { Reduction }\end{array}$ & $\begin{array}{l}\text { Government and } \\
\text { Regulatory }\end{array}$ \\
\hline
\end{tabular}

However, the immediate issue is whether the twelve sectors should form new groupings (for example be used as minor groups or unit groups) at the higher levels of the ANZSCO classification structure. This would be out of scope of the next minor review.

The O*NET breakdown tends to align with the approach taken by Human Resources and Skills Development Canada. 
activities and technologies identifying new occupations limit themselves and therefore constrain any classification developments.

Human Resources and Skills Development Canada has developed an initial taxonomy for green jobs based upon sectors and associated occupations from the North American Industry Classification System (NAICS) and the National Occupational Classification (NOC). Five domains are identified to cover the 'green' economy. These are:

- Environmental Protection

- Green Energy

- Energy Efficient Construction

- Green Manufacturing and Transportation;

- Green Services

In this taxonomy the domains are further disaggregated into broad sectors within which, industry and occupation categories from the two classifications are identified. The domains and sectors have been listed in Appendix 1.

The HRSDC taxonomy currently lists 125 jobs in total.

Of all of these approaches, the definition used by the United States Bureau of Labor Statistics is probably the most practical for use within the ANZSCO classification. However this definition could be operationally enhanced by using the scopes defined within the O*NET definitions.

The issue with many proposals for a green job framework is that they focus on potential sectors of the labour market that may not exist yet, or for which the word 'green' is added to an existing industry or sector. This is sort of a top-down approach of identifying sectors then adding jobs or occupations, rather than the bottom-up approach of identifying the jobs and then seeing how they should be grouped in an occupation classification.

\section{What is meant by green jobs or occupations?}

Green jobs can span a wide range of skills, education, and occupations. As a result, statistical classifications have to change to provide government with information that recognises relevant employment in new and emerging industries as well as green employment across sectors.

It seems generally that there are three scenarios with identifying and measuring green jobs. There is (a) the situation of the job fundamentally staying the same but the working environment changing; (b) the situation where the purpose of the occupation may stay the same but the tasks, skills, and knowledge required have altered or changed; and (c) the emergence of a completely new occupation.

Each scenario requires a different approach from the classifications perspective but can they all be covered by one definition of green job? The reality is that an occupation classification has to be able to cover all three scenarios otherwise it is limiting its usefulness for analysing the labour market. So definitions which seek to "green" occupations based upon green economic

Green jobs are not just about the environment, sustainability or renewable energy, nor are they just about measuring change in professional occupations versus trades occupations. It is about identifying the green elements of all jobs and then prioritising them into a strategy for review and inclusion in the classification.

Much of the international research has focused on identifying potential green areas of the economy and then assigning existing and potentially new occupations into those areas. Consequently most of the jobs identified are existing jobs assigned to a framework based on the potential for them to be deemed green through aspects of the tasks performed. Examples would be architects, electricians, electrical engineers, conservation officers, and wildlife biologists. A better approach may have been to look at all the occupations and what they do, ignore where they work and in what industries, and then see what are the commonalities in terms of the green component. This may lead to a more precise measurement of what constitutes green jobs.

For ANZSCO the approach is to identify jobs and occupations and collect information on them to produce statistical data that is important. In the ANZSCO context there is the need to have sufficient persons reporting the job title in statistical surveys as criteria for considering inclusion in the classification structure. The tasks and duties of the job should be unique and different from existing occupations in the classification structure. The skills required may be the same or different as existing occupations and there must be user demand for the occupation to be included in the structure. (Refer Appendix 2 for Criteria for Inclusion as a Separate Occupation in ANZSCO).

The ability to add green jobs to the classification is dependent on the treatment and identification of all jobs across the New Zealand labour market spectrum using the ANZSCO criteria and not limiting coverage to just professional or vocational or trades occupations.

As a result for ANZSCO, a working definition going forward may read like this. 'Green jobs are jobs that produce goods or provide services that benefit the environment or conserve natural resources through the use of sustainable, environmentally friendly, processes and technologies.'

\section{Green Skills}

Any definition of green jobs is constrained by the need to define the concept of green skills. For the production of labour market statistics, ANZSCO is a skills based classification which classifies occupations by skill level and skill specialisation.

Within the ANZSCO context, skills are defined by level and specialisation. Skill level is measured by the: 
- level or amount of formal education and training;

- amount of previous experience in a related occupation; and

- amount of on-the-job training.

Skill specialisation is defined as a function of the:

- $\quad$ field of knowledge required;

- $\quad$ tools and equipment used;

- materials worked on; and

- goods or services produced or provided.

Do green skills relate to new formal qualifications that reflect the need for knowledge that enables understanding of new technologies or processes or which change the competencies for occupational performance?

Do green skills reflect changes in the tools and equipment used, materials worked on, or goods and services produced for an occupation?

So what are green skills and do they differ from existing occupational skill sets or not? Much of the discussion is framed by how much the economy has 'greened' and whether the jobs are in fact new jobs or just repackaged existing jobs. Clearly defined green skills, in the context of the ANZSCO criteria, do not really exist at present as much of the technological change that would drive the need for new skills is still in its infancy. The focus, for industry and government is on creating new skills and training programmes to facilitate occupational change for green jobs.

An additional difficulty for classification development by a statistical agency is getting the right skills information from education providers or industry to place the occupation in the most appropriate sub-major group (two digit level) of ANZSCO. Quite often there is conflicting advice from within industry about the level of qualification or the amount of experience and training. This is where stakeholders working together can assist the statistical agency in reaching the right decision and having the right information.

It is not for ANZSCO to anticipate or provide a list of skills that will be in demand or will be emerging. The identification of new jobs in the classification will be based upon existing skill sets as currently defined in ANZSCO. To introduce new skill criteria into ANZSCO is not an option until the classification is given a full conceptual review tentatively scheduled for 2017. The skills information assists in the placement of occupations within the ANZSCO structure but is not the primary classification criteria for inclusion.

Many occupations may not require new skills or enhancement of existing skills. For example a bus driver that currently drives a diesel powered bus who switches to driving a biofuel or CNG powered bus will essentially not require any skill changes.

Some occupations may require on-the-job or short-term skill adjustments. For example a farmer that moves to organic farming or an energy broker moving to a carbon credit trade.

Other occupations may require longer training to enable technical skills to be learnt. For example a motor vehicle mechanic who repairs petrol driven cars needing to upskill to learn how to repair electric or hybrid cars.

New occupations that emerge will have new skill requirements. For example a wind energy developer or energy auditor will require specification of new qualifications and skills. For the statistical agencies, ensuring that the correct skill information is supplied, particularly the identification of new qualifications is very important to ensure that occupations are placed in the appropriate parts of the classification.

\section{Options for ANZSCO}

Options for ANZSCO are based upon the intention to undertake a minor review of the classification in 2013 in time for the 2016 Census of Population and Dwellings. All options that are discussed below are constrained by the need to reach agreement with the Australian Bureau of Statistics on (a) any review taking place; (b) what occupations to review and or add; and (c) what are the agreed skills and tasks to enable placement within the classification structure.

For a minor review this means that (a) new occupations can be added to the classification at the occupation (six digit) level; (b) occupation titles can be updated or changed; (c) alternative titles added; and (d) specialisations added. The inclusion of new unit groups and above is not permissible in a minor review and can only happen at the next major review, tentatively scheduled to occur in the period leading up to the 2021 Census of Population and Dwellings.

Changes to skill levels of existing occupations will probably only occur when the major review takes place, unless there is an identified need to update skill levels to reflect real world changes in the meantime. A key consideration when making changes to the classification is to minimise any time-series disruptions. However the creation of new occupations may not necessarily affect the time series unless these occupations are split out of existing occupations.

\section{Minor Review}

The first option for ANZSCO is to consider the inclusion of any new green job or occupation utilising the classification criteria at the occupation (six digit) level. This would be dependent on identifying unique new occupations for which there is sufficient demand to collect statistics about, and for which there was sufficient information around which to describe in the classification. Examples of new occupations may include Sustainability Advisor or Energy Auditor.

This option is constrained by the need to identify specific qualifications, training, and experience as well as separate 
tasks and duties for inclusion at the occupation level of the classification.

\section{Alternative Titles and/or Tasks}

The second option is to consider the addition of alternative titles to existing occupation categories. This would be used for occupations that are becoming significant but which do not quite meet the criteria for separate inclusion in the classification structure. This would probably lead to additional tasks being added and can be done for any existing occupation. An example of alternative titles may be adding Sustainability and Reporting Analyst to the existing Environmental Research Scientist occupation category.

\section{Specialisations}

The third option is to consider the addition of specialisations to existing occupations. This would be used for occupations that are (a) similar to an existing occupation and which are not unique enough to qualify for separate inclusion, or (b) actual job titles associated with a specific occupation. This can be done for any existing occupation. An example of a specialisation might be adding Carbon Credit Broker to Commodities Trader, or adding Wind Resource Analyst to Environmental Research Scientist.

\section{Alternative View}

A final option is to create an alternative view of the classification for green jobs comprising all existing jobs and/or any new occupations that have been added to the classification. Alternative views are thematic crosscutting groupings of occupations developed to facilitate a meaningful and consistent comparison of employment in various 'sectors'. Whether this approach is feasible would require stakeholder consultation and a clear definition of green jobs, as potentially all occupations could be considered green in some way.

\section{Conclusions}

Undoubtedly ANZSCO provides the best statistical framework for classifying and measuring green jobs. The primary issue for ANZSCO is establishing an agreed definition between the Australian and New Zealand statistical agencies of what is a green job. This will frame any future developments and changes to the classification in terms of identifying new occupational categories for inclusion or amendment of existing occupational categories. The discussion then has to turn to agreement between the statistical agencies on skills and tasks that are required for each occupation that is added to or amended in the classification.

However the inclusion of significant classification category changes cannot really be undertaken until the next major review of the classification, currently proposed for around 2017. Creating a 'green' classification going forward will require some key conceptual adjustments to ANZSCO as there will be a need to consider the changes to qualifications and industry that will occur as the New Zealand labour market and economy becomes more green. In the meantime opportunity exists to at least add alternative titles or specialisations in ANZSCO to advance recognition of green jobs, as well as possible inclusion of new occupations within the existing framework. 


\section{Notes}

The Occupational Information Network (O*NET) is a source of occupational information developed by the US Department of Labor/Employment and Training Administration. It uses the United States Standard Occupational Classification (SOC) as the base framework.

\section{References}

Australian Bureau of Statistics [ABS] and Statistics New Zealand (2009). Australian and New Zealand Standard Classification of Occupations (ANZSCO) $\left(1^{\text {st }}\right.$ ed, rev 1). Canberra: Australian Bureau of Statistics.

Career Services rapuara (2010) Green jobs. Retrieved October 2010 from

(http://www2.careers.govt.nz/home_page.html)

Ehmcke. W., Philipson, G. and Kold-Christensen, C. (2009). Who are the Green Collar Workers? Retrieved October 2010 from (http://www.connectionresearch.com.au/RecentPro jects)

European Centre for the Development of Vocational Training. (2010). Skills for green jobs: (European Synthesis Report). Luxembourg: European Centre for the Development of Vocational Training.

Hancock. A. (2008). Australian and New Zealand Standard Classification of Occupations (ANZSCO): The Impact of a Trans-Tasman Classification on Labour Market Data. In P. Morrison (ed.) $13^{\text {th }}$ Conference on Labour Employment and Work in New Zealand (399-406). Wellington: School of Geography, Environmental and Earth Sciences, Victoria University of Wellington.

National Center for O*NET Development (2009). Greening of the World of Work, Implications for O*NET-SOC and New and Emerging Occupations. Washington DC: National Center for O*NET Development.

OECD (2010). Interim Report of the Green Growth Strategy: Implementing our commitment for a sustainable future. Paris: Meeting of the OECD Council at Ministerial Level.

UNEP, ILO, IOE, ICTU (2008). Green jobs: Towards decent work in a sustainable, low-carbon world. (2008). Kenya: United Nations Environment Programme.
Author

Andrew Hancock

Classifications and Standards

Statistics New Zealand

Private Bag 4741

Christchurch

Andrew.Hancock@stats.govt.nz 


\section{Appendix 1: Taxonomy for Green Jobs}

Human Resources and Skills Development Canada (HRSDC)

\begin{tabular}{|c|c|}
\hline Domain & Sector \\
\hline Energy Efficient Construction & $\begin{array}{l}\text { Geothermal Heating } \\
\text { Green Buildings } \\
\text { Retrofitting of Apartment and Office Buildings } \\
\text { Solar Heating and Cooling }\end{array}$ \\
\hline Environmental Protection & $\begin{array}{l}\text { Carbon Sequestration/Carbon Storage and Capture } \\
\text { Environmental Policy, Regulation, Control, \& Monitoring } \\
\text { Environmental Site Assessment } \\
\text { Landfill, Land Use, and Right of Way Planning } \\
\text { Landscaping } \\
\text { Pollution Prevention, Abatement, and Control } \\
\text { Recycling } \\
\text { Reforestation and Forestry } \\
\text { Soil Conservation and Decontamination/Brownfields } \\
\text { Redevelopment/Reclamation and Remediation Services } \\
\text { Solid Waste Disposal } \\
\text { Sustainable Agriculture, Organic Farming/Harvesting } \\
\text { Waste Management, Sewerage, and Wastewater Services } \\
\text { Wildlife, Fisheries, and Habitat Protection }\end{array}$ \\
\hline Green Manufacturing and Transportation & $\begin{array}{l}\text { Electrical Equipment, Appliance and Component Manufacturing } \\
\text { Fabricated Metal Product Manufacturing } \\
\text { Hybrid-Electric, Electric, and Fuel Cell Vehicles } \\
\text { Machinery Manufacturing } \\
\text { Paper Manufacturing } \\
\text { Petroleum and Coal Product Manufacturing } \\
\text { Plastics and Rubber Products Manufacturing }\end{array}$ \\
\hline Green Services & $\begin{array}{l}\text { Advocacy } \\
\text { Building Inspection } \\
\text { Eco-Tourism } \\
\text { Energy Traders } \\
\text { Environmental Assessments, Audits, and Compliance } \\
\text { Environmental Testing } \\
\text { Financial Services/Venture Capital } \\
\text { Green Education and Training } \\
\text { Green Research } \\
\text { Research, Design, and Consulting Services }\end{array}$ \\
\hline Green Energy & $\begin{array}{l}\text { Biofuel and Biomass Projects } \\
\text { Co-generation } \\
\text { Geothermal Projects } \\
\text { Greenhouse Gas Management } \\
\text { Hydroelectricity } \\
\text { Nuclear Power } \\
\text { Smart Grid Technologies } \\
\text { Solar Power Projects } \\
\text { Tidal Energy Projects } \\
\text { Wind Power Projects }\end{array}$ \\
\hline
\end{tabular}




\section{Appendix 2: Criteria for Inclusion as a Separate Occupation in ANZSCO}

For an occupation to be included in its own right in the ANZSCO structure it must meet certain criteria. These are:

- That at least 100 persons report employment in the occupation in the New Zealand Census of Population and Dwellings;

- That the skill requirements make it unique/different from other occupations in both Australia and New Zealand;

- That the tasks and duties make it unique/distinct from other occupations in both Australia and New Zealand;

- That it is statistically feasible to collect information about the occupation ie that people will actually respond with that title in a statistical survey or administrative collection in both Australia and New Zealand;

- That it is an occupation that can be legally performed in either Australia, or New Zealand, or both;

- That there is stakeholder consensus in both Australia and New Zealand to include the occupation;

- Maintaining time series and international comparability;

- That there is stakeholder demand - subject to the above criteria;

NB: Occupations are not included just to meet skill shortages or immigration requirements. 